\title{
Tensile Mechanical Properties and Strengthening Mechanism of Hybrid Carbon Nanotube and Silicon Carbide Nanoparticle-Reinforced Magnesium Alloy Composites
}

\author{
Xia Zhou, ${ }^{1}$ Depeng Su, ${ }^{1}$ Chengwei Wu, ${ }^{1}$ and Liming Liu ${ }^{2}$ \\ ${ }^{1}$ State Key Laboratory of Structural Analysis for Industrial Equipment, Department of Engineering Mechanics, \\ Faculty of Vehicle Engineering and Mechanics, Dalian University of Technology, Dalian 116024, China \\ ${ }^{2}$ School of Materials Science and Engineering, Dalian University of Technology, Dalian 116024, China
}

Correspondence should be addressed to Xia Zhou, zhouxia@dlut.edu.cn

Received 1 February 2012; Revised 10 June 2012; Accepted 25 June 2012

Academic Editor: Tianxi Liu

Copyright (C) 2012 Xia Zhou et al. This is an open access article distributed under the Creative Commons Attribution License, which permits unrestricted use, distribution, and reproduction in any medium, provided the original work is properly cited.

\begin{abstract}
AZ91 magnesium alloy hybrid composites reinforced with different hybrid ratios of carbon nanotubes (CNTs) and silicon carbide ( $\mathrm{SiC})$ nanoparticulates were fabricated by semisolid stirring assisted ultrasonic cavitation. The results showed that grains of the matrix in the $\mathrm{AZ91} /(\mathrm{CNT}+\mathrm{SiC})$ composites were obviously refined after adding hybrid CNTs and $\mathrm{SiC}$ nanoparticles to the AZ91 alloy, and the room-temperature mechanical properties of AZ91/(CNT + SiC) hybrid composites were improved comparing with the unreinforced AZ91 matrix. In addition, the tensile mechanical properties of the AZ91 alloy-based hybrid composites were considerably improved at the mass hybrid ratio of 7:3 for CNTs and SiC nanoparticles; in particular, the tensile and yield strength were increased, respectively, by about 45 and 55\% after gravity permanent mould casting. The reason for an increase in the room-temperature strength of the hybrid composites should be mainly attributable to the larger hybrid ratio of CNTs and SiC nanoparticles, the coefficient of thermal expansion (CTE) mismatch between matrix and hybrid reinforcements, the dispersive strengthening effects (Orowan strengthening), and the grain refining (Hall-Petch effect).
\end{abstract}

\section{Introduction}

Magnesium-based composites as a result of their low density and superior mechanical properties are potential candidates for applications in aerospace, automobile, transportation, and consumer industries where weight saving is of great importance [1]. Many attempts have been directed in recent years towards the development of $\mathrm{Mg}$-based composites with nanoparticulates such as $\mathrm{Al}_{2} \mathrm{O}_{3}, \mathrm{Y}_{2} \mathrm{O}_{3}, \mathrm{SiC}, \mathrm{AlN}$, and/or carbon nanotubes (CNTs) [2,3] using different methods such as powder metallurgy, casting, rapid solidification, and in situ fabrication. In addition, the investigations by many researchers [4-8] have shown that variation of strength and ductility of magnesium can be realized through the use of ceramic reinforcements at nanolength scale. AZ91 alloy system has been paid much attention because of its widespread use in engineering applications. Results of the literature research indicated that mechanical behavior of nanaometersized particle or fiber-reinforced metal matrix composites has been primarily investigated, whereas a relatively little amount of research is conducted to investigate mechanical behavior of nanaometer-sized particulate and fiber hybrid reinforced metal matrix composites. Investigations carried out by Deng et al. [9] illustrated that mechanical properties of AZ91 magnesium matrix composites reinforced with submicron-SiC particulates were improved significantly. Li et al. [10] produced multiwalled carbon nanotube (MWCNT) reinforced magnesium alloy composites with high compressive strength by a predispersing procedure of CNTs on Mg alloy chips followed by a strongly melt stirring technique. Thakur et al. [11] showed the improvement in yield strength, ultimate tensile strength, and strain to failure when CNT/Mg composites was hybridized with nanoparticles of alumina. Tun and Gupta [12] reported microstructure and improved 
tensile properties of magnesium/(yttria + nickel) hybrid composites using hybrid microwave sintering. The literature research, however, revealed that no attempt is made to assess the effect of CNTs and SiC nanoparticulates on the mechanical properties of AZ91 $\mathrm{Mg}$ alloy. It is still a challenging task to synthesis bulk-sized engineering materials with homogeneous distribution of hybrid nanometer-sized reinforcements and to discuss the hybrid reinforcement mechanism. The ultrasonic cavitation-based solidification processing [13] has a potential predominance for dispersing nanometer-sized particles or fibers in metal melts.

The hybrid composites in the present study were synthesized using the self-designed ultrasonic cavitation technique coupled with semisolid mechanical stirring method. Focus is placed in this study to correlate the mechanical properties with the microstructural characteristics due to copresence of SiC nanoparticle and CNT reinforcements. The tensile mechanical properties and fracture behavior of hybrid composites are compared with that of AZ91 alloy to justify their development. The enhancing mechanism of the hybrid composites is finally discussed.

\section{Experimental Procedures}

2.1. Materials and Processing. In this study, Bulk AZ91 magnesium alloy with a nominal composition of Mg-9.0Al$0.95 \mathrm{Zn}-0.2 \mathrm{Mn}$ (acquired from Shenyang Research Institute of Foundry, China) was used as the matrix material. The beta-SiC with a particulate size range of $30 \mathrm{~nm}$ (supplied with Jiuyuan Nano-materials Inc., Sichuan, China) and MWCNT with an average diameter of $50 \mathrm{~nm}$ and a length of 1-5 $\mu \mathrm{m}$ (procured from Nanotech Port Inc., Shenzhen, China) were used as the hybrid reinforcements. The TEM morphology of the hybrid reinforcements is shown in Figure 1 after they were pretreated by purification, surface modification, and ultrasonic dispersion. AZ91 Mg alloy/ $(\mathrm{CNT}+\mathrm{SiC})$ hybrid composites with different hybrid ratios were synthesized using self-designed semisolid stirring assisted ultrasonic cavitation method.

Figure 2 shows the schematic experimental setup for the semisolid stirring assisted ultrasonic processing of CNT and $\mathrm{SiC}$ nanoparticle-reinforced magnesium matrix composites. The whole experiments were carried out with the protection of $0.5 \% \mathrm{SF}_{6}+\mathrm{N}_{2}$. The protective gas mixture of $\mathrm{N}_{2}$ and $\mathrm{SF}_{6}$ with a volume ratio of $1000: 1.8$ can prevent magnesium alloy from evaporation and avoid burning by the compact surface film [14] formed on molten magnesium alloy. First, about $1 \mathrm{~kg}$ of AZ91 alloy was melted at $720^{\circ} \mathrm{C}$ and then cooled to $590^{\circ} \mathrm{C}$ at which the matrix alloy was in semisolid condition; the pretreated CNTs and SiC nanoparticles were fed into the semisolid Mg alloy melt from a steel tube. The total mass content of CNTs and SiC nanoparticles in the $\mathrm{AZ91/(CNT}+\mathrm{SiC})$ composites was 1.0 mass \% while the hybrid mass ratio of CNTs and $\mathrm{SiC}$ nanoparticles was different. The semisolid stirring speed and time for the AZ91/ $(\mathrm{CNT}+\mathrm{SiC})$ composites were $1000 \mathrm{r} / \mathrm{min}$ and $20 \mathrm{~min}$, respectively. After adequately stirring the melt, the melt was rapidly reheated to $700^{\circ} \mathrm{C}$ for $5 \mathrm{~min}$. Then the ultrasonic probe made of titanium was dipped into the melt for about

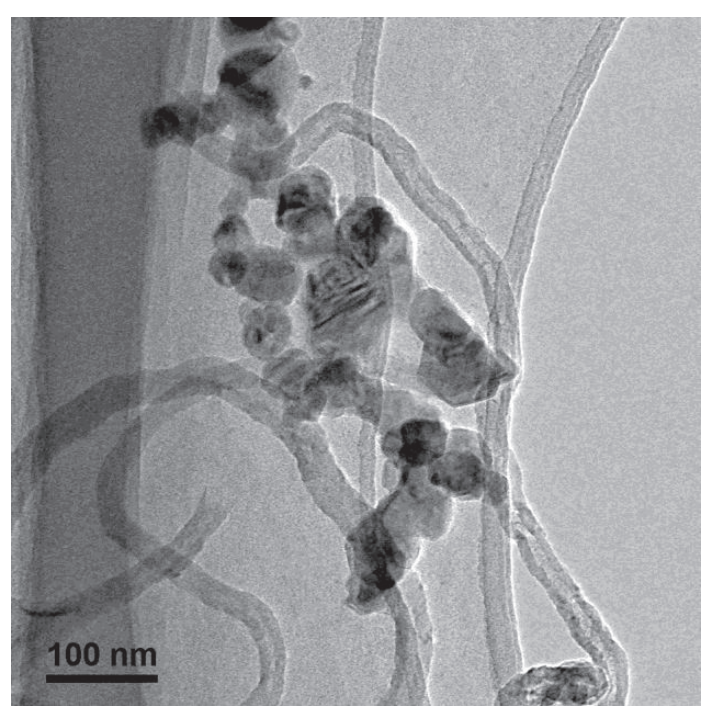

FIGURE 1: TEM micrograph of composite powder.

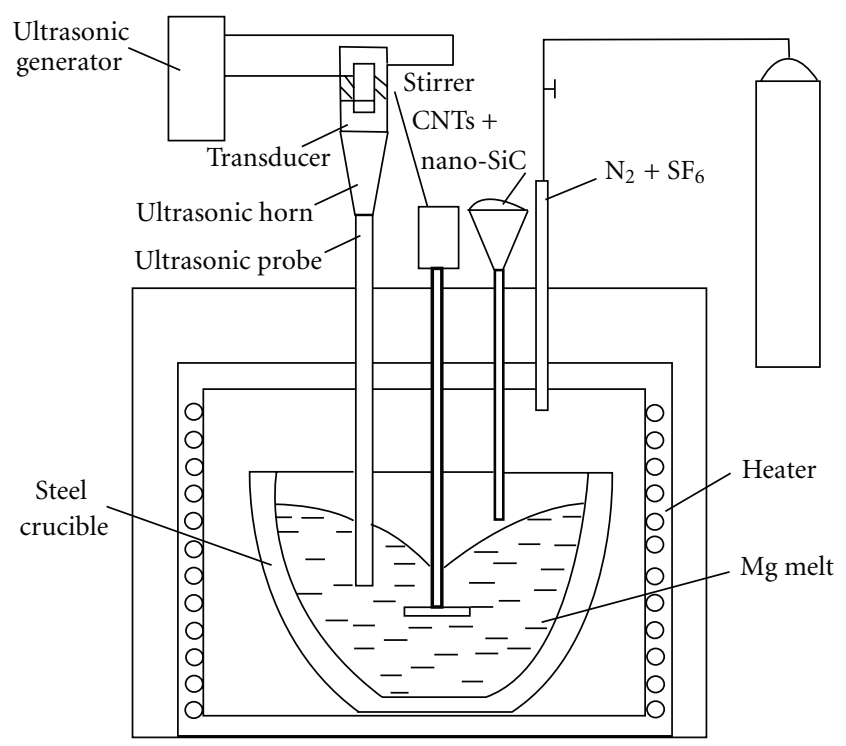

FIGURE 2: Schematic of the experimental setup for fabricating $\mathrm{AZ91/(CNT}+\mathrm{SiC})$ composites.

$35 \mathrm{~mm}$ after the stirrer was removed from the melt. The ultrasonic processing device consists of a transducer with a maximum power of $4 \mathrm{~kW}$ and frequency of about $18 \mathrm{kHz}$. The melt was ultrasonically processed for $20 \mathrm{~min}$ before the ultrasonic probe was removed. Then the melt was elevated to a pouring temperature of $720^{\circ} \mathrm{C}$ and cast into a steel permanent mold which was preheated to $450^{\circ} \mathrm{C}$. For comparison, an AZ91 alloy sample without semisolid stirring assisted ultrasonic processing was also cast under the same conditions.

\subsection{Microstructural Characterization and Tensile Mechanical} Behavior. The microstructural and fracture surface characterization studies of the composites were carried out using 


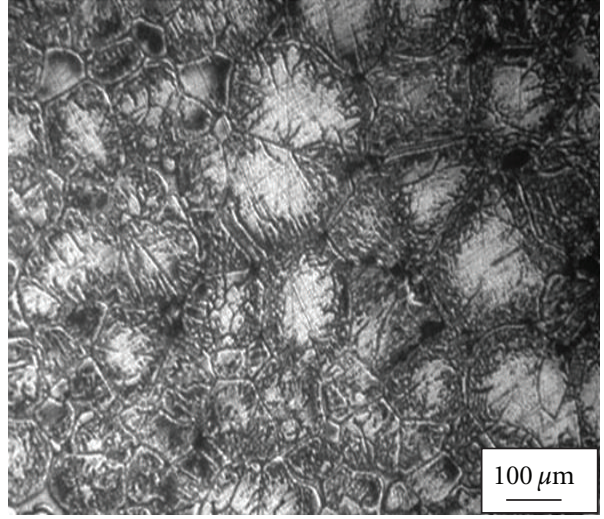

(a)

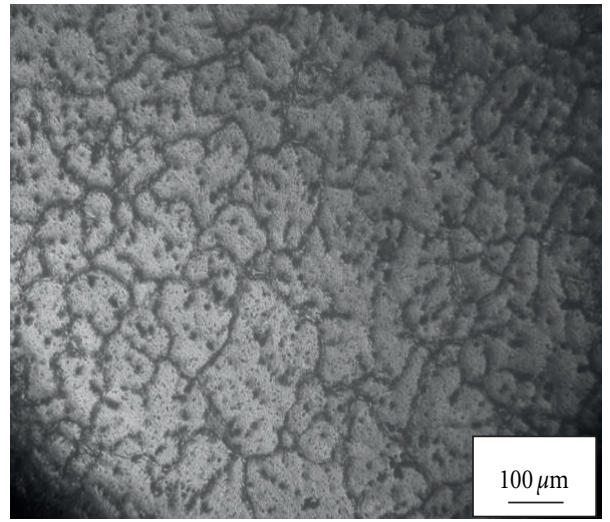

(b)

Figure 3: Optical micrographs of (a) AZ91 Mg alloy matrix and (b) AZ91/(0.7\% CNT + 0.3\% SiC) composites. Here, AZ91/(0.7\% CNT + $0.3 \% \mathrm{SiC}$ ) refers to the hybrid $\mathrm{CNT} / \mathrm{SiC}$ nanoparticle mass ratio of $7: 3$ and the hybrid content of 1.0 mass $\%$ in this composite, and so on.

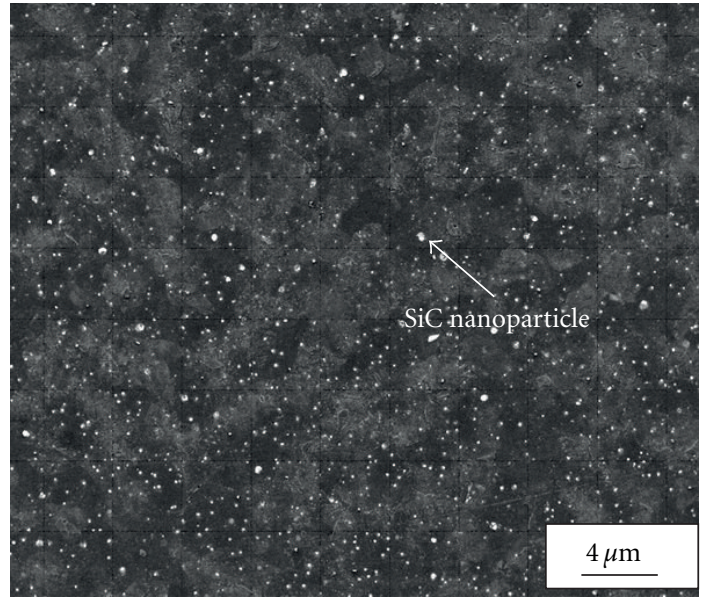

(a)

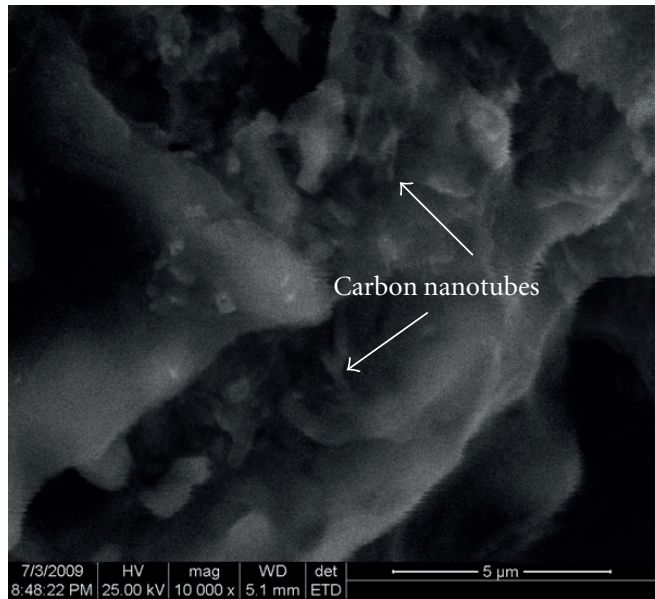

(b)

FIGURE 4: High-magnification SEM images of (a) the SiC nanoparticles distributed in the as-cast AZ91/(0.7\% CNT + 0.3\% SiC) and (b) the CNTs distributed in the fractograph of the hybrid composites.

a XJG-05 optical microscope, a JSM-5600LV SEM, and a TECNAI G2205-TWIN TEM, respectively. The tensile tests were conducted on 3354 Instron tensile testing machine using round tension test specimens of $5 \mathrm{~mm}$ diameter and $25 \mathrm{~mm}$ gauge length at a nominal strain rate of $2 \times 10^{-3} \mathrm{~s}^{-1}$.

\section{Results and Discussion}

3.1. Microstructure of AZ91 Hybrid Composites. The optical micrographs of the as-cast AZ91 Mg alloy and the AZ91 Mg-alloy-based hybrid composites are shown in Figure 3. It is observed that the coarse grain structure of AZ91 Mgalloy (Figure 3(a)) is refined significantly when the hybrid content in the AZ91/(0.7\% CNT + 0.3\% SiC) composites increases to 1.0 mass \% (Figure 3(b)). Here, AZ91/(0.7\% $\mathrm{CNT}+0.3 \% \mathrm{SiC}$ ) refers to the hybrid $\mathrm{CNT} / \mathrm{SiC}$ nanoparticle mass ratio of $7: 3$ and the hybrid content of 1.0 mass $\%$ in this composite, and so on. Representative SEM images of the $\mathrm{AZ91} /(0.7 \% \mathrm{CNT}+0.3 \% \mathrm{SiC})$, shown in Figure 4, indicate a relatively good dispersion of $\mathrm{SiC}$ nanoparticles (Figure 4(a)) and CNTs (Figure 4(b)) in the matrix. Under the acoustic cavitations and acoustic stream effects produced by high intensity ultrasonic treatment, the introduction of the nanoparticles and CNTs into the matrices provides some heterogeneous nucleation sites during solidification, and as a result, the grain size of the matrix in the AZ91/(CNT + SiC) composites is obviously decreased while the distribution of CNTs and SiC nanoparticles is improved in the AZ91 Mgalloy based hybrid composites. This can be considered as the main prerequisite for achieving good mechanical properties.

Figure 5 shows a more high magnification TEM image of the AZ91 Mg alloy based hybrid composite along with selected area diffraction patterns (SADPs) of two areas. From the TEM image of this composite shown in Figure 5, it can be seen that the nanometer-sized $\mathrm{SiC}$ particles and CNTs are uniformly distributed in the area observed. In the SADP from the marked A area in Figure 5, there are diffuse haloes due to the amorphous carbon film on the copper grid and sharp 


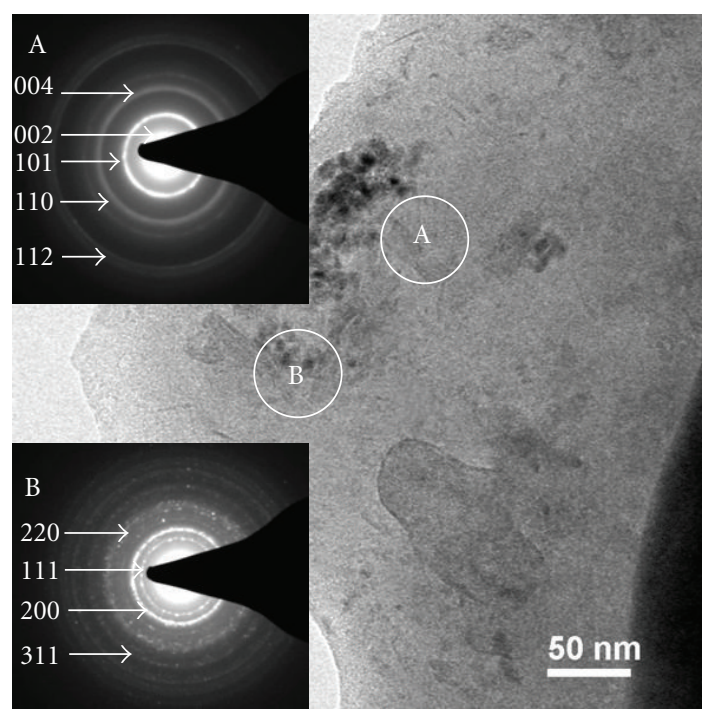

FIGURE 5: TEM image and SADPs of two selected areas of the AZ91 Mg-alloy-based hybrid composites showing the presence of hybrid composite structure.

rings due to the MWCNTs. The D-spacing values of the first five clear rings were found to be in good agreement with those of MWCNT's (002), (101), (004), (110), and (112), and this can also be proved by the experimental result of Belin and Epron [15]. In the SADP from the marked B area in Figure 5, with the exception of diffraction rings from the MWCNT, the corresponding diffraction pattern can be indexed as (111), (200), (220), and (311), and this matches well with the cubic $\beta$-SiC [16]. The TEM studies have showed the hybrid composite microstructure was obtained in the AZ91 Mg-based composites, manifested by the coexistence of nanaometer-sized $\beta$-SiC diffraction spots and MWCNT sharp rings with central haloes of the amorphous carbon film.

3.2. Tensile Stress-Strain Curves and Tensile Properties. Tensile stress-strain curves for the pure AZ91 magnesium alloy and the CNT filled as well as nanometer-sized SiC filled composites are shown in Figure 6. It exhibits that the pure AZ91 magnesium alloy, the $\mathrm{SiC}$ nanoparticle filled $\mathrm{AZ} 91$, and CNT filled AZ91 composites show a brittle type of curves, but the addition of $\mathrm{SiC}$ nanoparticles or CNTs results in little increase in the yield and tensile strength. This may be related to the nonuniform distribution of nanoparticles and CNTs when their adding amounts are larger [17].

Figure 7 shows the stress-strain curves of AZ91/(CNT + $\mathrm{SiC})$ hybrid composites with different hybrid ratios. It can be seen that hybrid composites also show a similar type of curves as do CNT- or SiC-reinforced composites, but the change from linear to nonlinear deformation occurs at a higher stress in the former case probably because of the coexistence of CNTs and $\mathrm{SiC}$ nanoparticles. The yield strength, maximum tensile stress, and elongation rate at break of the hybrid composites increased with the increase of hybrid mass ratio between CNTs and SiC nanoparticles. When the

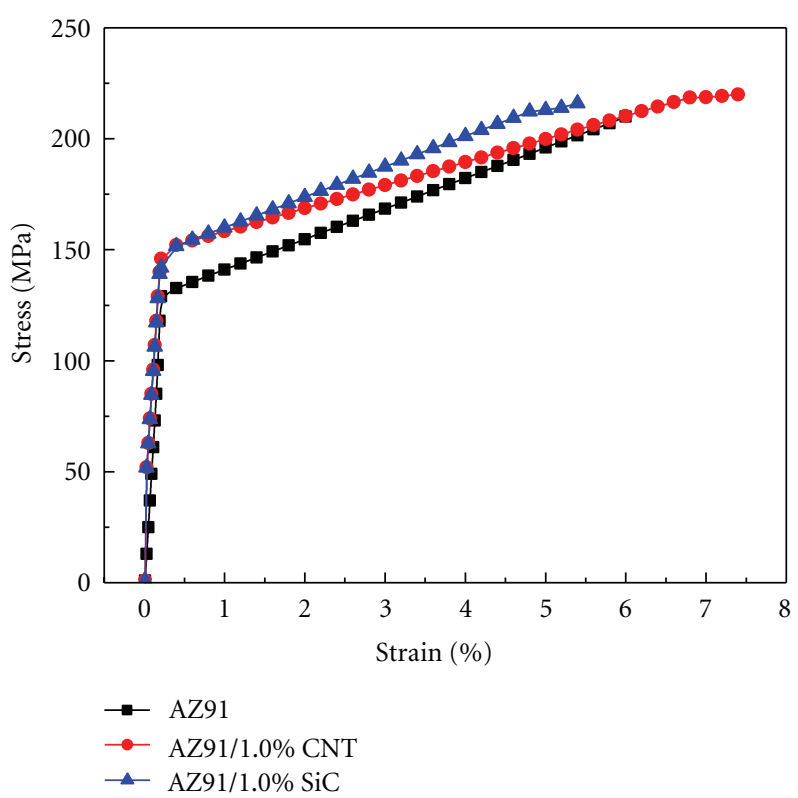

Figure 6: Stress-strain curves of AZ91 magnesium alloy, 1.0 mass $\%$ CNT reinforced AZ91 (AZ91/1.0\% CNT) and 1.0 mass \% $\mathrm{SiC}$ nanoparticle-reinforced AZ91 (AZ91/1.0\% SiC) composites obtained by tensile test.

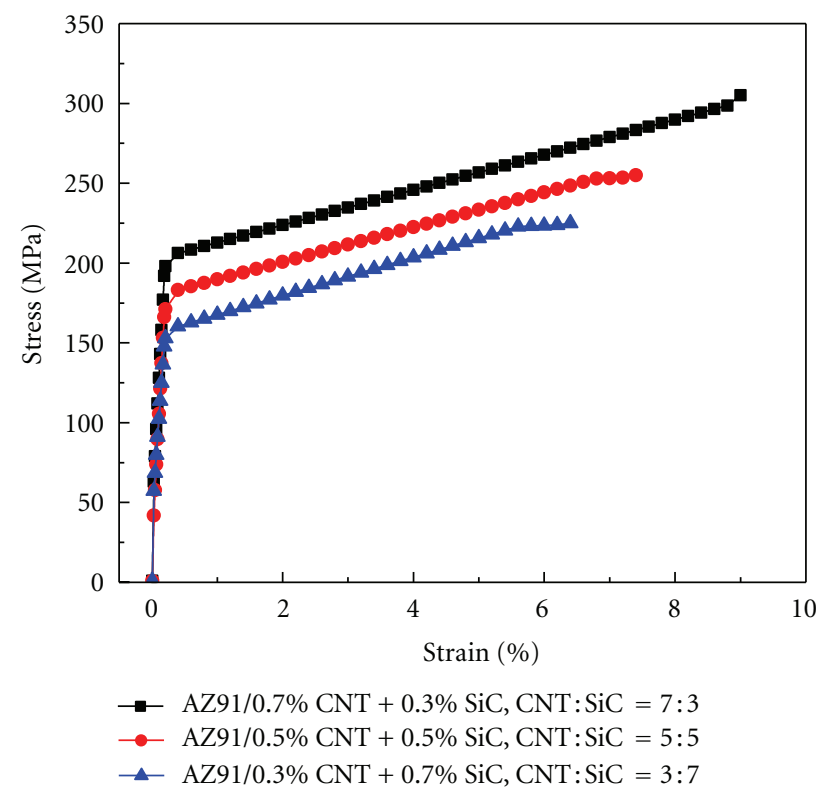

Figure 7: Stress-strain curves of AZ91/(CNT + SiC) hybrid composites with different hybrid ratios.

hybrid mass ratio of $\mathrm{CNTs}$ and $\mathrm{SiC}$ nanoparticles ranged between $5: 5$ and $7: 3$, the tensile mechanical properties of the hybrid composites were much better than those of the AZ91 magnesium alloy. In particular, when the mass ratio of CNTs and SiC nanoparticles was $7: 3$, the tensile strength and elongation of the hybrid composite reached the maximums at the same time. The maximum tensile strength and elongation were up to $305 \mathrm{MPa}$ and $9 \%$, respectively; 


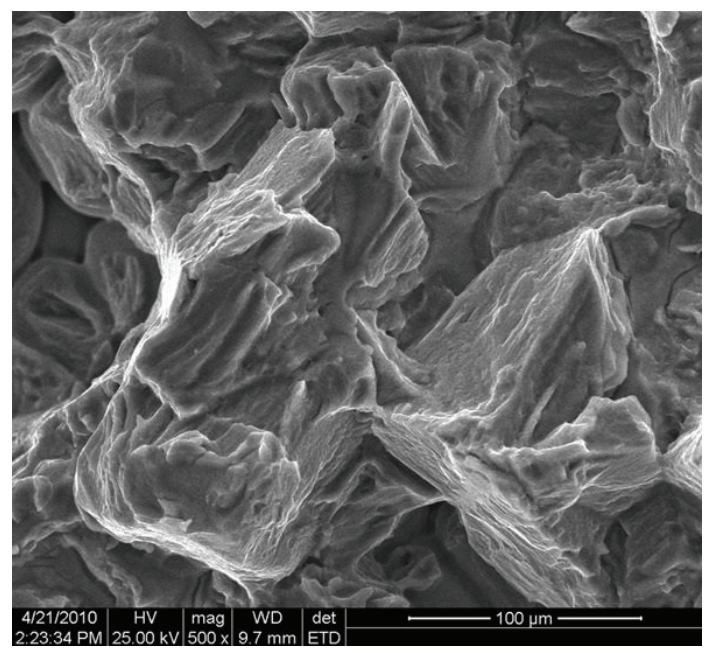

(a)

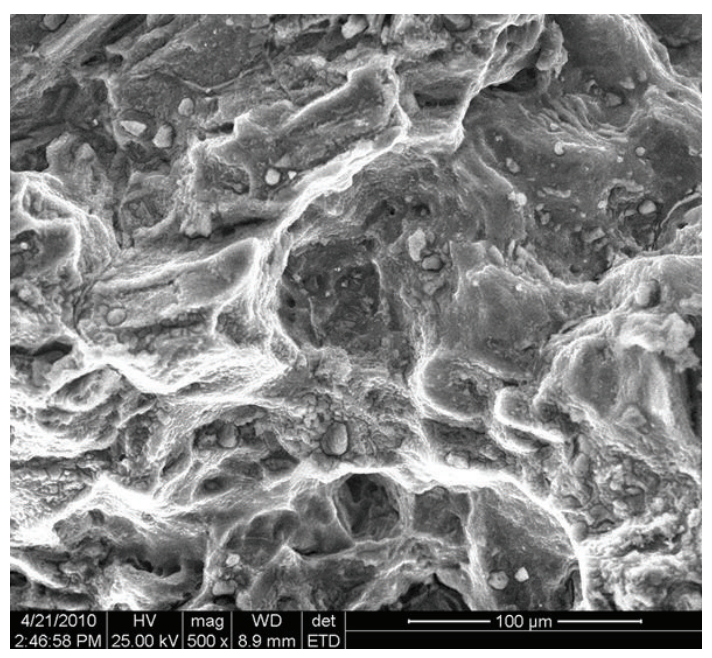

(b)

Figure 8: Representative SEM fractographs of: (a) AZ91 Mg-alloy and (b) AZ91/(0.7\% CNT + 0.3\% SiC).

they increased by 45 and 50\% compared with those of the AZ91 magnesium alloy matrix. As revealed by the fractured surfaces of the tensile specimens in Figure 8, significant improvements in tensile properties were accompanied by a transition from a brittle fracture (Figure 8(a)) for as-cast AZ91 Mg-alloy to quasi-cleavage fracture state (Figure 8(b)) for $\mathrm{AZ} 91 /(0.7 \% \mathrm{CNT}+0.3 \% \mathrm{SiC})$.

3.3. Strengthening Mechanisms. The improvement in the yield strength due to four factors including the load-bearing effect, coefficient of thermal expansion (CTE) mismatch, Orowan strengthening, and Hall-Petch effect can be coupled together using the quadrature method [18-20] or another method given by Ramakrishnan based on the modified shear lag model [21]. However, the cases of the hybrid composites especially reinforced by both particles and fibers are not taken into account in the two above-mentioned methods. The improvement in yield strength is expressed as follows:

$$
\begin{aligned}
& \Delta \sigma_{\text {total }} \\
& \quad=\sqrt{\left(\Delta \sigma_{\text {Load }}\right)^{2}+\left(\Delta \sigma_{\text {CTE }}\right)^{2}+\left(\Delta \sigma_{\text {Orowan }}\right)^{2}+\left(\Delta \sigma_{\text {Hall-Petch }}\right)^{2}}
\end{aligned}
$$

The load bearing effect, $\Delta \sigma_{\text {load }}$, is caused by the shear transfer of load from the matrix to the particles and is represented by

$$
\Delta \sigma_{\text {load }}=0.5 V_{P} \sigma_{y m}
$$

where $\sigma_{y m}$ is the yield stress of AZ91 matrix reinforced with CNTs considering hybrid effects, its value is obtained by experiments, $\sigma_{y m}=128.5 \mathrm{MPa}$.
The improvement in yield strength, $\Delta \sigma_{\mathrm{CTE}}$, due to the generation of geometrically necessary dislocations to accommodate the CTE mismatch between the particle and matrix is given by Dai et al. [22] as follows:

$$
\begin{gathered}
\Delta \sigma_{\mathrm{CTE}}=\sqrt{3} \beta G_{m} b \sqrt{\frac{12 V_{P} \Delta \alpha \Delta T}{\left(1-V_{p}\right) b d_{P}}}, \\
\Delta \sigma_{\text {Orowan }}=\frac{0.13 G_{m} b}{d_{P}\left[\left(1 / 2 V_{P}\right)^{1 / 3}-1\right]} \ln \frac{d_{P}}{2 b}, \\
\Delta \sigma_{\text {Hall-Petch }}=k_{y} d_{m}^{-1 / 2},
\end{gathered}
$$

where $V_{P}$ and $d_{P}$ are the volume fraction and diameter of $\mathrm{SiC}$ particles, respectively; $d_{m}$ is corrected as the grain size of AZ91 matrix reinforced with CNTs; $\Delta \alpha$ is the difference in coefficients of thermal expansion between AZ91 matrix reinforced with CNTs and SiC; $\Delta T$ is the difference between the processing and the test temperatures. $\beta$ and $k_{y}$ are constants, $G_{m}$ is the shear modulus of AZ91 Mg alloy matrix reinforced with CNTs, and $b$ is the Burgers vector of CNT reinforced AZ91 matrix. The above mentioned data for the $\mathrm{SiC}$ nanoparticle and CNT-reinforced magnesium composites tested at room temperature are used $V_{P}=0.0055$, $d_{P}=50 \mathrm{~nm}, d_{m}=1.15 \times 10^{-4} \mathrm{~m}, \Delta \alpha=22.0 \times 10^{-6} \mathrm{~K}^{-1}$, $\Delta T=375 \mathrm{~K}, \beta=1.25, k_{y}=0.1 \mathrm{MNm}^{-3 / 2}, G_{m}=E_{m} /[2(1+$ $v)]=45 /[2(1+0.3)]=17.3 \mathrm{GPa}$, and $b=0.32 \mathrm{~nm}$.

The contributions of different strengthening mechanisms to the yield stress of the AZ91/(CNT + SiC) composite were calculated using (1)-(5). The results are summarized in Table 1, where it can be observed that a final strength improvement of $73.1 \mathrm{MPa}$ is achieved. This is very close to the experimental $\Delta \sigma$ of about $73.5 \mathrm{MPa}$ determined from the stress-strain curves shown in Figures 6 and 7 for AZ91 Mg alloy and AZ91/(0.7\% CNT + 0.3\% SiC) hybrid composite, respectively. The main contributing factors come 
TABLE 1: Calculated contributions of different strengthening mechanisms to the yield stress of the AZ91/(0.7\% CNT $+0.3 \% \mathrm{SiC})$ composites.

\begin{tabular}{lcccc}
\hline $\begin{array}{l}\Delta \sigma_{\text {Hall-Petch }} \\
(\mathrm{MPa})\end{array}$ & $\begin{array}{c}\Delta \sigma_{\mathrm{CTE}} \\
(\mathrm{MPa})\end{array}$ & $\begin{array}{c}\Delta \sigma_{\text {Orowan }} \\
(\mathrm{MPa})\end{array}$ & $\begin{array}{c}\Delta \sigma_{\text {load }} \\
(\mathrm{MPa})\end{array}$ & $\begin{array}{c}\Delta \sigma_{\text {total }} \\
(\mathrm{MPa})\end{array}$ \\
\hline 10.7 & 70.1 & 17.9 & 0.35 & 73.1 \\
\hline
\end{tabular}

from the large CTE difference between the nanosized hybrid reinforcements and the AZ91 Mg alloy matrix, the small size of the reinforcements and the grain refining effect. In addition, high hybrid ratio of CNTs and SiC nanoparticles is beneficial for load transfer, uniform distribution of hybrid reinforcements and their interfacial bonding with AZ91 magnesium alloy matrix [23]. In the present study, when the mass fraction of the hybrid reinforcements is given (1.0 mass \%), the higher the content of CNTs in the hybrid reinforcements is, the greater the elastic modulus and yield strength of the composites are, but when the ratio of CNT to $\mathrm{SiC}$ nanoparticle is higher than $7: 3$, the performance of the composites is less increased. On the other hand, SEM observations at high magnifications revealed apparently that interfacial reactions did not exist between hybrid reinforcement and the matrix due to surface pretreatment of the hybrid reinforcement. Thus, the mechanical properties of the AZ91 magnesium alloy are enhanced markedly by small amount of CNT and nanometer-sized SiC hybrid reinforcements.

\section{Conclusions}

(1) The addition of small amount of hybrid CNTs and $\mathrm{SiC}$ nanoparticles results in significant improvements in both tensile properties and toughness. The best strength properties of AZ91 Mg based composites are obtained at 1.0 mass \% of CNTs and SiC nanoparticles with the mass hybrid ratio of $7: 3$. Moreover, this causes a considerable increase in the ductility of the hybrid composites relative to the monolithic materials.

(2) Based on several kinds of improved strengthening mechanism model, it is shown that the yield strength of AZ91-based hybrid composites is mainly governed by the hybrid ratio of CNTs and $\mathrm{SiC}$ nanoparticles, the mismatch in the CTE between the matrix and nanometer-sized reinforcements, Orowan strengthening, and grain refinement effects. The overall strengthening effect is related to the hybrid ratio of CNTs and SiC nanoparticles. The larger the hybrid ratio is, the higher the strength of the hybrid composite is. The improved model shows excellent agreement with the experimental data.

\section{Acknowledgment}

The authors gratefully acknowledge the financial support from the Natural Science Foundation Project of Liaoning Province of China (201102040).

\section{References}

[1] C. S. Goh, J. Wei, L. C. Lee, and M. Gupta, "Development of novel carbon nanotube reinforced magnesium nanocomposites using the powder metallurgy technique," Nanotechnology, vol. 17, no. 1, pp. 7-12, 2006.

[2] J. Lan, Y. Yang, and X. Li, "Microstructure and microhardness of SiC nanoparticles reinforced magnesium composites fabricated by ultrasonic method," Materials Science and Engineering A, vol. 386, no. 1-2, pp. 284-290, 2004.

[3] G. Cao, H. Choi, J. Oportus, H. Konishi, and X. Li, "Study on tensile properties and microstructure of cast AZ91D/AlN nanocomposites," Materials Science and Engineering A, vol. 494, no. 1-2, pp. 127-131, 2008.

[4] S. F. Hassan and M. Gupta, "Development of high performance magnesium nano-composites using nano- $\mathrm{Al}_{2} \mathrm{O}_{3}$ as reinforcement," Materials Science and Engineering A, vol. 392, no. 1-2, pp. 163-168, 2005.

[5] W. L. E. Wong and M. Gupta, "Simultaneously improving strength and ductility of magnesium using nano-size SiC particulates and microwaves," Advanced Engineering Materials, vol. 8, no. 8, pp. 735-740, 2006.

[6] C. S. Goh, J. Wei, L. C. Lee, and M. Gupta, "Properties and deformation behaviour of $\mathrm{Mg}-\mathrm{Y}_{2} \mathrm{O}_{3}$ nanocomposites," Acta Materialia, vol. 55, no. 15, pp. 5115-5121, 2007.

[7] S. F. Hassan and M. Gupta, "Development and characterization of ductile $\mathrm{Mg} / \mathrm{Y}_{2} \mathrm{O}_{3}$ nanocomposites," Journal of Engineering Materials and Technology, vol. 129, no. 3, pp. 462-467, 2007.

[8] K. S. Tun and M. Gupta, "Improving mechanical properties of magnesium using nano-yttria reinforcement and microwave assisted powder metallurgy method," Composites Science and Technology, vol. 67, no. 13, pp. 2657-2664, 2007.

[9] K. K. Deng, K. Wu, Y. W. Wu, K. B. Nie, and M. Y. Zheng, "Effect of submicron size $\mathrm{SiC}$ particulates on microstructure and mechanical properties of AZ91 magnesium matrix composites," Journal of Alloys and Compounds, vol. 504, no. 2, pp. 542-547, 2010.

[10] Q. Q. Li, A. Viereckl, C. A. Rottmair, and R. F. Singer, "Improved processing of carbon nanotube/magnesium alloy composites," Composites Science and Technology, vol. 69, no. 7-8, pp. 1193-1199, 2009.

[11] S. K. Thakur, T. S. Srivatsan, and M. Gupta, "Synthesis and mechanical behavior of carbon nanotube-magnesium composites hybridized with nanoparticles of alumina," Materials Science and Engineering A, vol. 466, no. 1-2, pp. 32-37, 2007.

[12] K. S. Tun and M. Gupta, "Development of magnesium/ (yttria + nickel) hybrid nanocomposites using hybrid microwave sintering: microstructure and tensile properties," Journal of Alloys and Compounds, vol. 487, no. 1-2, pp. 76-82, 2009.

[13] Y. Yang and X. Li, "Ultrasonic cavitation-based nanomanufacturing of bulk aluminum matrix nanocomposites," Journal of Manufacturing Science and Engineering, vol. 129, no. 2, pp. 252-255, 2007.

[14] G. Pettersen, E. Øvrelid, G. Tranell, J. Fenstad, and H. Gjestland, "Characterisation of the surface films formed on molten magnesium in different protective atmospheres," Materials Science and Engineering A, vol. 332, no. 1-2, pp. 285-294, 2002.

[15] T. Belin and F. Epron, "Characterization methods of carbon nanotubes: a review," Materials Science and Engineering B, vol. 119, no. 2, pp. 105-118, 2005.

[16] J. Z. Guo, Y. Zuo, Z. J. Li, W. D. Gao, and J. L. Zhang, "Preparation of $\mathrm{SiC}$ nanowires with fins by chemical vapor deposition," Physica E, vol. 39, no. 2, pp. 262-266, 2007. 
[17] S. Y. Liu, W. Z. Li, X. Y. Jia, F. P. Gao, and Q. Y. Zhang, "Preparation and properties of nano-sized $\mathrm{SiC}$ particles reinforced AZ91D magnesium matrix composites," Rare Metal Materials and Engineering, vol. 39, no. 1, pp. 134-138, 2010 (Chinese).

[18] B. Q. Han and D. C. Dunand, "Microstructure and mechanical properties of magnesium containing high volume fractions of yttria dispersoids," Materials Science and Engineering A, vol. 277, no. 1-2, pp. 297-304, 2000.

[19] F. Tang, I. E. Anderson, T. Gnaupel-Herold, and H. Prask, "Pure Al matrix composites produced by vacuum hot pressing: tensile properties and strengthening mechanisms," Materials Science and Engineering A, vol. 383, no. 2, pp. 362-373, 2004.

[20] Z. Zhang and D. L. Chen, "Consideration of Orowan strengthening effect in particulate-reinforced metal matrix nanocomposites: a model for predicting their yield strength," Scripta Materialia, vol. 54, no. 7, pp. 1321-1326, 2006.

[21] N. Ramakrishnan, "An analytical study on strengthening of particulate reinforced metal matrix composites," Acta Materialia, vol. 44, no. 1, pp. 69-77, 1996.

[22] L. H. Dai, Z. Ling, and Y. L. Bai, "Size-dependent inelastic behavior of particle-reinforced metal-matrix composites," Composites Science and Technology, vol. 61, no. 8, pp. 10571063, 2001.

[23] S. R. Bakshi and A. Agarwal, "An analysis of the factors affecting strengthening in carbon nanotube reinforced aluminum composites," Carbon, vol. 49, no. 2, pp. 533-544, 2011. 

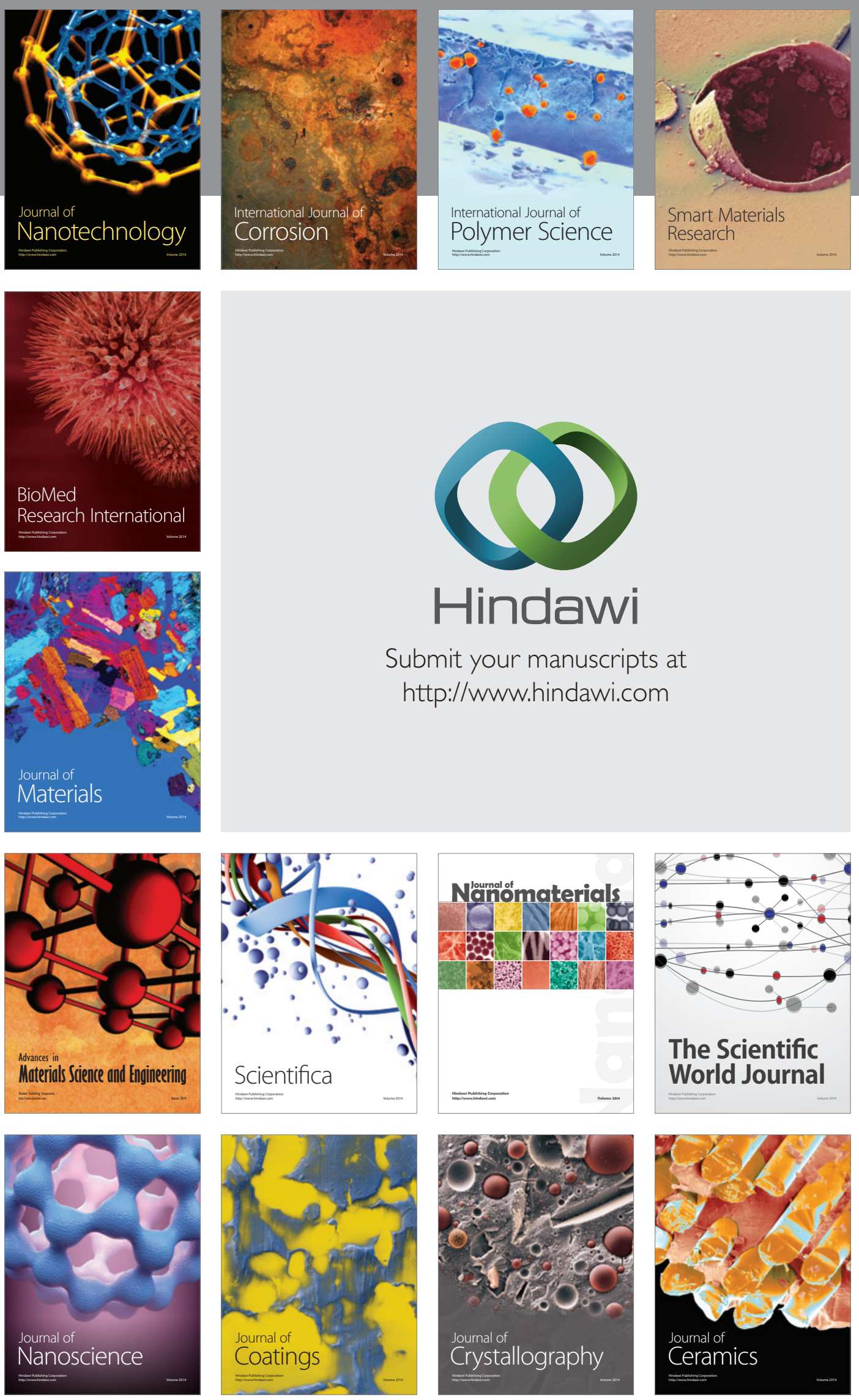

The Scientific World Journal

Submit your manuscripts at

http://www.hindawi.com

\section{World Journal}

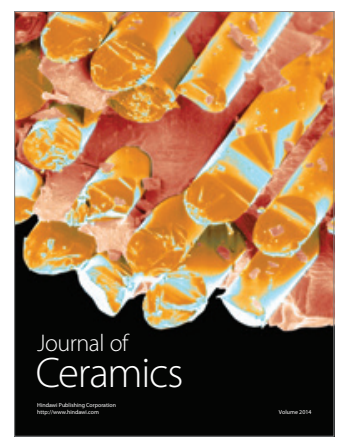

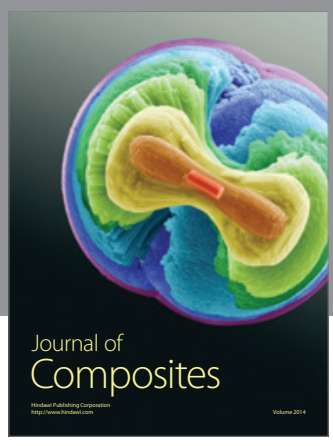
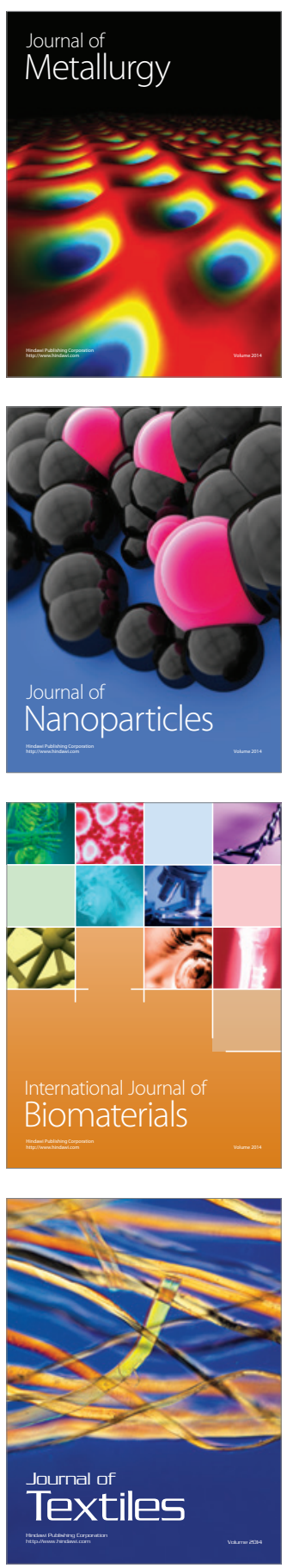